\title{
Analisis Pengaruh Proses Belajar Mengajar dan Fasilitas Pendidikan Terhadap Prestasi Belajar Taruna TLB IX di Poltekbang Surabaya
}

\author{
Aulia Regia, SP \\ R. Moh Radix Agustiono
}

Politeknik Penerbangan Surabaya

Jl. Jemur Andayani I/73 Surabaya

\begin{abstract}
Teaching and learning activities at Aviation Polytechnic of Surabaya are conducted with highly supportive learning facilities, the creation of convenience is the key to improving the quality and results of graduate quality. Adequate classrooms, supportive practice tools, and learning methods that are always updated in accordance with the latest curriculum in the world of aviation are all created for cadets to have competitiveness and competence to compete in the world of work. Result of F Test calculation done with SPSS program is got value of F count equal to 157,135. The value of significance obtained is 0.001, the value of this significance is smaller than the value of $\alpha$ is 0.05 . Thus Ho is rejected and Ha accepted, meaning that the independent variables of teaching and learning process (XI) and educational facilities (X2) together affect the variable tied learning achievement (Y) cadet electrical engineering airport force IX at Aviation Polytechnic of Surabaya. In Partial Tests obtained results: For learning process variables / (XI), the value of t arithmetic is 9,464 and the significance value is 0,000, this value is smaller than $\alpha=0,05$ thus means that the learning process variables XI) partially has a significant influence on the dependent variable achievement learning $(Y)$ cadet electrical engineering airport force IX at Aviation Polytechnic of Surabaya. For the educational facilities variable / (X2), the value of tarithmetic is 7,913 and the significance value is 0.000, this value is smaller than $\alpha=0,05$ so it means that the educational facility variable (X2) partially has significant influence to the variable tied learning achievement $(Y)$ cadet electrical engineering airport force IX at Aviation Polytechnic of Surabaya. From the results of SPSS about partial correlation coefficient, it is known that the variable XI is the learning process has the highest partial correlation value is 0.832 compared with other independent variables. Therefore, the variable X1 is the variable teaching and learning process is the independent variable that predominantly affects the dependent variable is the learning achievement $(Y)$ cadet electrical engineering airport force IX at Aviation Polytechnic of Surabaya.
\end{abstract}

Keywords : teaching and learning, graduate quality, learning methods, curriculum.

\section{Latar Belakang Masalah}

Kegiatan proses belajar mengajar di Politeknik Penerbangan Surabaya dilaksanakan dengan fasilitas belajar yang sangat mendukung, terciptanya kenyamanan adalah kunci utama untuk meningkatkan mutu hasil dan kualitas lulusan. Ruang kelas yang memadai, peralatan praktek yang mendukung, dan metode pembelajaran yang selalu update sesuai dengan kurikulum terbaru di dunia penerbangan semuanya kami ciptakan agar taruna mempunyai daya saing dan kompetensi untuk dapat bersaing di dunia kerja, beberapa fasilitas pendukung yang ada di Politeknik Penerbangan Surabaya mempunyai 14 Ruang kelas dengan kapasitas kelas 30 orang dan setiap kelas dilengkapi Air Conditioner serta Laptop dan LCD Proyektor dan beberapa diantaranya menggunakan whiteboard magnetic dengan system toutchscreen yang disesuaikan dengan perkembangan teknologi yang sedang berkembang dan sebaga i sarana pendukung proses belajar mengajar di kelas. Laboratorium elektronika pendukung yang ada di Politeknik Penerbangan Surabaya Guna mengaplikasi dari kajian teori ke dalam praktek maka dalam 
pelaksanaan praktikum didukung dengan Laboratorium/Workshop Laboratoirum ini berkapasitas 20 orang yang dilengkapi dengan 20 unit Komputer yang terintergrasi untuk praktek bahasa inggris dengan sistem komunikasi 2 arah dan 2 desk operator untuk 2 orang Instruktur Laboratorium komputer yang ada di Politeknik Penerbangan Surabaya untuk metode pembelajaran dikemas sedemikian rupa agar anak didik dapat dengan lebih mudah dan lebih interaktif mempelajari setiap komponen yang ada dengan teknik trouble shooting, dengan media modul praktek

Bertitik tolak dari upaya untuk menumbuhkan motivasi guna mencapai kinerja yang diharapkan, maka penulis tertarik untuk mengambil judul dalam penelitian ini sebagai berikut : "Analisis Pengaruh Proses Belajar Mengajar dan Fasilitas Pendidikan terhadap Prestasi Belajar Taruna Teknik Listrik Bandara Angkatan IX di Politeknik Penerbangan Surabaya"

\section{Metode Penelitian}

Berdasarkan tujuan yang ingin dicapai dalam rencana penelitian ini yaitu : menjelaskan pengaruh variabel bebas / independen terhadap variabel terikat / dependen, maka penelitian ini termasuk ke dalam jenis penelitian penjelasan (explanatory research). Penelitian ini berusaha menjelaskan hubungan kausal yang terjadi antara variabel-variabel penelitian dan menguji hipotesa yang telah dirumuskan sebelumnya.

\section{Populasi dan Sampel Penelitian}

Sebelum melakukan penelitian terlebih dahulu kita harus menentukan sejumlah elemen yang dijadikan obyek penelitian yang merupakan satuan analisa, yang disebut populasi. Populasi menurut Malo $(1986,149)$ pada dasarnya adalah himpunan semua hal yang ingin ketahui dan biasanya disebut sebagai universum. Singarimbun $(1986 ; 108)$ juga menyatakan bahwa populasi atau universe adalah jumlah keseluruhan unit analisa yang ciri-cirinya akan diduga. Arikunto (2002) menyatakan bahwa populasi adalah keseluruhan subyek penelitian.

Berkaitan dengan pengertian diatas, maka yang menjadi populasi dalam penelitian ini adalah 24 taruna teknik listrik bandara angkatan IX di Politeknik Penerbangan Surabaya.

Sehubungan jumlah subyek ( anggota ) didalam populasi tidak begitu banyak maka, penelitian ini dilakukan pada seluruh subyek populasi, artinya 24 taruna teknik listrik bandara angkatan IX di Politeknik Penerbangan Surabaya menjadi obyek atau responden penelitian. Dengan kata lain metode pengambilan sampelnya adalah metode sensus.

\section{Jenis Dan Sumber Data}

Data yang dibutuhkan dalam penelitian ini dapat digolongkan menjadi dua jenis yaitu :

1. Data Primer

Data ini meliputi data tentang prestasi belajar taruna teknik listrik bandara angkatan IX di Politeknik Penerbangan Surabaya, proses belajar mengajar, fasilitas pendidikan. Data ini diperoleh dari responden yaitu taruna teknik listrik bandara angkatan IX di Politeknik Penerbangan Surabya melalui penyebaran kuisioner dan studi dokumentasi.

2. Data sekunder

Data yang dibutuhkan antara lain adalah obyek penelitian yaitu Politeknik Penerbangan Surabaya. 


\section{Cara Pengumpulan Data}

Pengumpulan data dilaksanakan dengan mengarahkan kuisioner kepada responden, kuisioner yang sudah diisi diperiksa kembali untuk dipilih kuisioner yang memenuhi syarat dan yang tidak memenuhi syarat dalam pengisiannya. Informasi diperoleh melalui :

1. Penyebaran kuisioner, cara ini ditempuh untuk mendapatkan data tentang variabel proses belajar mengajar dan fasilitas pendidikan, dengan mengajukan sejumlah peryataan / pertanyaan yang harus direspon oleh responden dengan cara memilih salah satu alternatif jawaban yang telah disediakan. Responden yang telah memberikan tanggapan secara pribadi sesuai dengan pandangan, pengalaman dan pendapatnya secara jujur, akan dianalisis sesuai dengan teknik analisis yang akan digunakan untuk menguji hipotesis yang ditetapkan dalam penelitian ini.

2. Studi dokumentasi, digunakan untuk mengungkapkan data prestasi belajar taruna teknik listrik bandara angkatan IX di Politeknik Penerbangan Surabaya yang menjadi sampel / responden dalam penelitian ini

\section{Uji F (uji bersama)}

Pengujian ini digunakan untuk mengukur tingkat signifikansi secara bersama antara variabel bebas yaitu proses belajar mengajar (X1) dan fasilitas pendidikan (X2) terhadap variabel terikat prestasi belajar (Y) taruna teknik listrik bandara angkatan IX di Akademi Teknik.

Adapun hasil pengolahan SPSS diperoleh signifikansi pada nilai fhitung sebagi berikut :

\section{Tabel 1}

Nilai F hitung dan signifikansi

ANOVA

\begin{tabular}{|ll|r|r|r|r|c|}
\hline Model & & \multicolumn{1}{c|}{$\begin{array}{c}\text { Sum of } \\
\text { Squares }\end{array}$} & df & Mean Square & F & Sig. \\
\hline 1 & Regression & 1238.706 & 3 & .702 & 157.135 & $.001^{\mathrm{a}}$ \\
& Residual & 166.200 & 20 & 5.208 & & \\
& Total & 1404.905 & 23 & & & \\
\hline
\end{tabular}

a. Predictors: (Constant), X3, X2, X1

b. Dependent Variable: $Y$

Sumber : Lampiran hasil Olahan SPSS

Sesuai dengan hasil perhitungan Uji F yang dilakukan dengan bantuan program SPSS diperoleh nilai $F$ hitung sebesar 157,135. Nilai signifikansi yang diperoleh adalah sebesar 0,001 , nilai signifikansi ini lebih kecil daripada nilai $\alpha$ yaitu 0,05 . Dengan demikian Ho ditolak dan Ha diterima, artinya variabel bebas yaitu proses belajar mengajar (X1) dan fasilitas pendidikan(X2) secara bersama berpengaruh terhadap variabel terikat prestasi belajar (Y) taruna teknik listrik bandara angkatan IX di Politeknik Penerbangan Surabaya.

\section{Uji t (uji parsial)}

Pengujian ini digunakan untuk mengukur tingkat signifikansi secara parsial antara variabel bebas yaitu proses belajar mengajar (X1) dan fasilitas pendidikan (X2) terhadap variabel terikat prestasi belajar (Y) taruna teknik listrik bandara angkatan IX di Politeknik Penerbangan.

Adapun hasil pengolahan SPSS diperoleh signifikansi pada nilai thitung sebagi berikut : 
Tabel 2

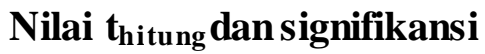

Coefficients

\begin{tabular}{|c|c|c|c|c|c|c|c|c|c|c|c|}
\hline \multirow{2}{*}{\multicolumn{2}{|c|}{ Model }} & \multicolumn{2}{|c|}{$\begin{array}{c}\text { Unstandardized } \\
\text { Coefficients }\end{array}$} & \multirow{2}{*}{$\begin{array}{c}\begin{array}{c}\text { Standardized } \\
\text { Coefficients }\end{array} \\
\text { Beta }\end{array}$} & \multirow[b]{2}{*}{$t$} & \multirow[b]{2}{*}{ Sig. } & \multicolumn{3}{|c|}{ Correlations } & \multicolumn{2}{|c|}{ Collinearity Statistics } \\
\hline & & B & Std. Error & & & & Zero-order & Partial & Part & Tolerance & VIF \\
\hline 1 & (Constant) & 61.141 & .979 & & 62.543 & .000 & & & & & \\
\hline & $X 1$ & 8.461 & 1.810 & 1.788 & 9.464 & .000 & .912 & .832 & .692 & .798 & 1.575 \\
\hline & $X 2$ & 7.134 & 1.491 & 1.347 & 7.913 & .000 & .889 & .790 & .625 & .973 & 1.325 \\
\hline
\end{tabular}

a. Dependent Variable: $Y$

\section{Sumber : Lampiran Hasil Olahan SPSS}

Dari hasil perhitungan dengan uji t diatas maka dapat di interprestasikan sebagai berikut:

1. Untuk variabel proses belajar mengajar / (X1), nilai t hitung yang diperoleh adalah sebesar 9,464 dan nilai signifikansinya adalah 0,000 , nilai ini lebih kecil daripada $\alpha=0,05$, sehingga Ho ditolak dan Ha diterima yang berarti bahwa variabel proses belaj ar mengajar (X1) secara parsial memiliki pengaruh signifikan terhadap variabel terikat prestasi belajar (Y) taruna teknik listrik bandara angkatan IX di Politeknik Penerbangan Surabaya.

2. Untuk variabel fasilitas pendidikan / (X2), nilai t hitung yang diperoleh adalah sebesar 7,913 dan nilai signifikansinya adalah 0,000 , nilai ini lebih kecil daripada $\alpha=0,05$, sehingga Ho ditolak dan Ha diterima yang berarti bahwa variabel fasilitas belajar (X2) secara parsial memiliki pengaruh signifikan terhadap variabel terikat prestasi belajar $(\mathrm{Y})$ taruna teknik listrik bandara angkatan IX di politeknik Penerbangan Surabaya.

\section{Koefisien korelasi parsial}

Koefisien korelasi parsial menunjukkan pengaruh mana yang paling dominan dari variabel bebas yaitu bebas yaitu proses belajar mengajar (X1) dan fasilitas pendidikan (X2) terhadap variabel terikat yaitu prestasi belajar (Y) taruna teknik listrik bandara angkatan IX di Politeknik Penerbangan Surabaya.

\section{Tabel 3}

\section{Koefisien Korelasi Parsial}

\begin{tabular}{|c|c|c|c|c|c|c|c|c|c|c|c|}
\hline \multicolumn{12}{|c|}{ Coefficients $\mathrm{s}^{\mathrm{a}}$} \\
\hline \multirow[b]{2}{*}{ Model } & & \multicolumn{2}{|c|}{$\begin{array}{c}\text { Unstandardized } \\
\text { Coefficients }\end{array}$} & \multirow{2}{*}{$\begin{array}{c}\text { Standardized } \\
\text { Coefficients } \\
\text { Beta } \\
\end{array}$} & \multirow[b]{2}{*}{ t } & \multirow[b]{2}{*}{ Sig. } & \multicolumn{3}{|c|}{ Correlations } & \multicolumn{2}{|c|}{ Collinearity Statistics } \\
\hline & & $B$ & Std. Error & & & & Zero-order & Partial & Part & Tolerance & VIF \\
\hline & (Constant) & 61.141 & .979 & & 62.543 & .000 & & & & & \\
\hline & $\mathrm{X} 1$ & 8.461 & 1.810 & 1.788 & 9.464 & .000 & .912 & .832 & .692 & .798 & 1.575 \\
\hline & $X 2$ & 7.134 & 1.491 & 1.347 & 7.913 & .000 & .889 & .790 & .625 & .973 & 1.325 \\
\hline
\end{tabular}

a. Dependent Variable: $Y$

\section{Sumber : Lampiran Hasil Olahan SPSS}

Dari hasil olah SPSS mengenai koefisien korelasi parsial, maka diketahui bahwa variabel X1 yaitu proses belajar mengajar memiliki nilai korelasi parsial tertinggi yaitu 0,832 dibandingkan dengan variabel bebas yang lainnya. Oleh sebab itu maka variabel X1 yaitu 
variabel proses belajar mengajar merupakan variabel bebas yang dominan mempengaruhi variabel terikat yaitu prestasi belajar (Y) taruna teknik listrik bandara angkatan IX di Politeknik Penerbangan Surabaya.

\section{Kesimpulan}

Dari hasil pengujian yang penulis lakukan, maka dapat disimpulkan sebagai berikut :

1. Pada Pengujian secara bersama / sumultan diperoleh hasil :

Hasil perhitungan Uji F yang dilakukan dengan bantuan program SPSS diperoleh nilai F hitung sebesar 157,135. Nilai signifikansi yang diperoleh adalah sebesar 0,001, nilai signifikansi ini lebih kecil daripada nilai $\alpha$ yaitu 0,05 . Dengan demikian Ho ditolak dan Ha diterima, artinya variabel bebas yaitu proses belajar mengajar (X1) dan fasilitas pendidikan (X2) secara bersama berpengaruh terhadap variabel terikat prestasi belajar (Y) taruna teknik listrik bandara angkatan IX di Politeknik Penerbangan Surabaya

2. Pada Pengujian secara Parsial diperoleh hasil :

a. Untuk variabel proses belajar mengajar / (X1), nilai t hitung yang diperoleh adalah sebesar 9,464 dan nilai signifikansinya adalah 0,000, nilai ini lebih kecil daripada $\alpha=$ 0,05, sehingga Ho ditolak dan Ha diterima yang berarti bahwa variabel proses belajar mengajar (X1) secara parsial memiliki pengaruh signifikan terhadap variabel terikat prestasi belajar (Y) taruna teknik listrik bandara angkatan IX di Politeknik Penerbangan Surabaya.

b. Untuk variabel fasilitas pendidikan / (X2), nilai t hitung yang diperoleh adalah sebesar 7,913 dan nilai signifikansinya adalah 0,000 , nilai ini lebih kecil daripada $\alpha=0,05$, sehingga Ho ditolak dan Ha diterima yang berarti bahwa variabel fasilitas pendidikan (X2) secara parsial memiliki pengaruh signifikan terhadap variabel terikat prestasi belajar (Y) taruna teknik listrik bandara angkatan IX di politeknik Penerbangan Surabaya.

3. Dari hasil olah SPSS mengenai koefisien korelasi parsial, maka diketahui bahwa variabel $\mathrm{X} 1$ yaitu proses belajar mengajar memiliki nilai korelasi parsial tertinggi yaitu 0,832 dibandingkan dengan variabel bebas yang lainnya. Oleh sebab itu maka variabel X1 yaitu variabel proses belajar mengajar merupakan variabel bebas yang dominan mempengaruhi variabel terikat yaitu prestasi belajar (Y) taruna teknik listrik bandara angkatan IX di Politeknik Penerbangan Surabaya.

\section{DAFTAR PUSTAKA}

Ali, Mohammad, 2008, Penelitian Kependidikan Prosedur Dan Strategi, Penerbit Angkasa. Bandung.

Ali, H Muhammad. 2006 . Guru dalam Proses Belajar Mengajar, Penerbit Angkasa Bandung.

Baharuddin dan Esa Nur Wahyuni, 2008, Teori Belajar dan Pembelajaran, Penerbit Ar-ruzz Media, Yogyakarta

Chayhan, S.S., 1979, Innovation In Teaching Learing Processes, New Dehli: Vikas Publishing Hoyse, Pvt. Ltd

De Cecco, John P, \& William Crawford, 1977, The Psychology Of Learing And Teaching, Education Psychology, New Dehli: Precite-Hall Of India, Private Lt Siswoyo, Dwi, 2011, Ilmu Pendidikan, Penerbit UNY Press, Yogyakarta: 
Prayitno, Elida, 2009, Motivasi dalam Belajar. Penerbit Departemen Pendidikan dan Kebudayaan Direkorat Jenderal Pendidikan Tinggi, Jakarta.

Flippo, Edwin B. dan Moch. Masud, 2008, Manajemen Personalia, Jilid II, Penerbit Erlangga, Jakarta.

Flippo, Edwin B, 2009. Manajemen Personalia, jilid II, Edisi Ke-9, Erlangga, Jakarta.

Gagne, Robert M., 2010, The Conditions Of Learing, New York: Holt, Rinehart \& Winstone

Grondlund, Norman E., 2014, Individualizing Classroom Instruction, New York: Mac Milan Publishing Co

Hadjar, Ibnu, 2006, Strategi Membangun Motivasi Dalam Pembelajaran Orang Dewasa, Cipta Intelektual, Bandung .

Handoko, T Hani, 2006. Manajemen Personalia Dan Sumber Daya Manusia, penerbit, BPFE, Yogyakarta

Maunah, Binti, 2009, Ilmu Pendidikan. Penerbit Teras, Yogyakarta.

Mimbar Pendidikan, 2000, Pendidikan Berwawasan Jender, Edisi Nomor 2 Tahun XIX 2000, Bandung, University Press Universitas Pendidikan Indonesia.

Mimbar Pendidikan, 1999, Politik Pendidikan, Edisi Nomor 4 Tahun XVIII 1999, University Press Universitas Pendidikan Indonesia, Bandung.

Mimbar Pendidikan, 2000, Pendidikan Menuju Indonesia Baru, Edisi Nomor 1 Tahun XIX 2000, University Press Universitas Pendidikan Indonesia, Bandung. 